\title{
INFLUENCE OF METHODS OF ARC SURFACING WITH FLUX-CORED WIRE ON PENETRATION OF BASE METAL AND FORMATION OF DEPOSITED METAL
}

\author{
A.A. BABINETS ${ }^{1}$, I.A. RYABTSEV ${ }^{1}$, A.I. PANFILOV ${ }^{2}$, V.A. ZHDANOV $^{1}$ and I.I. RYABTSEV ${ }^{1}$ \\ ${ }^{1}$ E.O. Paton Electric Welding Institute, NASU \\ 11 Kazimir Malevich Str., 03680, Kiev, Ukraine. E-mail: office@paton.kiev.ua \\ ${ }^{2}$ OJSC «Steel Work» \\ 13 Tbilisskaya Str. 50005, Krivoy Rog, Ukraine
}

\begin{abstract}
The influence of methods of automatic arc surfacing on penetration of base metal, quality of formation and geometric sizes of deposited beads was investigated. In the experiments nine batches of flux-cored wires (25Kh5FMS type of deposited metal) of the diameter of 1.8; 2.4 and $2.8 \mathrm{~mm}$ for submerged arc, shielding gas and open arc surfacing were used. The surfacing was carried out in a wide range of modes: $I_{\mathrm{s}}=150-450 \mathrm{~A} ; U_{\mathrm{s}}=20-34 \mathrm{~V}$ at the same surfacing speed of $20 \mathrm{~m} / \mathrm{h}$. It was found that the greatest influence on formation of deposited beads is exerted by arc voltage. Moreover, the range of $\Delta U_{\mathrm{T}}$ voltages, at which a good formation of deposited beads and absence of pores is provided, does not coincide during surfacing by different methods with wire of the same diameter. The results obtained in this work can be used for selecting the method of arc surfacing, surfacing modes, which ultimately meet the operating conditions and the requirements to the deposited metal for definite parts. These results will be also used in databases in the development of computer programs for robotized additive technologies of arc surfacing. 13 Ref., 1 Table, 6 Figures.
\end{abstract}

Keywords: arc surfacing, surfacing modes, additive technologies of surfacing, flux-cored wire, deposited metal, penetration, formation of deposited metal

Flux-cored wire is one of the most universal electrode materials for mechanized and automated arc surfacing (welding) [1-3]. Among the main advantages of fluxcored wire, as compared to the other electrode materials, a rather simple adaptation of its chemical composition to the composition and properties of the parts being deposited, high arc burning stability, relatively low spattering of electrode metal and good formation of deposited beads can be mentioned [4-8].

Depending on the method of surfacing the fluxcored wires can be divided into three classes: for submerged arc surfacing, surfacing in the shielding gases and using open arc (self-shielding) [1, 9].

It is widely known, that the surfacing modes have a significant effect on penetration of base metal and quality of formation of deposited metal [1-10]. However, in most cases, the data presented in the mentioned works are uncoordinated, because they describe the properties of deposited metal produced using different methods applying different surfacing materials and modes. Moreover, when developing the technology for surfacing of different parts it is often necessary to provide not only the quality and preset properties of deposited metal, but also the specified geometric sizes of deposited beads and volume of base metal in the deposited metal (VBMD), etc. [9].
The aim of this work is the systematic investigation of influence of different methods of automatic arc surfacing and surfacing parameters on penetration of base metal, quality of formation and geometric sizes of deposited beads using surfacing materials of the same chemical composition and diameters.

The accumulation of databases on the modes of different methods of arc surfacing, geometric sizes of deposited beads, VBMD values and the value of penetration considering the previously developed expert systems on surfacing technologies $[11,12]$ and the proposed computer system advisor for selection of technology for surfacing typical parts [13] can further serve as a basis for development of computer programs for robotized additive technologies of arc surfacing.

Materials and methods of investigations. For investigations nine batches of experimental flux-cored wires were manufactured for submerged arc surfacing (AN-26P), shielding gas (82\% $\mathrm{Ar}+18 \% \mathrm{CO}_{2}$ ) and with open arc applying self-shielding flux-cored wire (shielding system $\mathrm{CaO}+\mathrm{TiO}_{2}+\mathrm{MgO}+\mathrm{CaF}_{2}+\mathrm{Al}_{2} \mathrm{O}_{3}$ ) of the diameters of 1.8; 2.4 and $2.8 \mathrm{~mm}$. The metallic part of the charge of flux-cored wires was calculated in the way to produce deposited metal of one type: 25Kh5FMS. For surfacing the universal surfacing installation U-653 was used, completed with the pow- 
Influence of surfacing mode using flux-cored wires of $1.8 \mathrm{~mm}$ diameter on formation of deposited metal and VBMD depending on the method of surfacing

\begin{tabular}{|c|c|c|c|c|c|}
\hline \multirow[b]{2}{*}{ Number } & \multicolumn{2}{|c|}{ Surfacing mode } & \multirow[b]{2}{*}{ Formation (presence of pores) } & \multirow[b]{2}{*}{ VBMD, \% } & \multirow[b]{2}{*}{ Appearance of deposited beads } \\
\hline & $I_{\mathrm{s}}, \mathrm{A}$ & $U_{s}, \mathrm{~V}$ & & & \\
\hline \multicolumn{6}{|c|}{ Submerged arc surfacing } \\
\hline 1 & 241 & 26.9 & Satisfactory. Narrow bead & 30.5 & \multirow{7}{*}{ 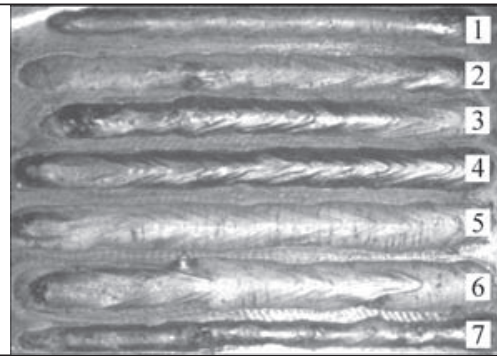 } \\
\hline 2 & 245 & 27.9 & Good & 44 & \\
\hline 3 & 290 & 27.8 & Poor & 44.5 & \\
\hline 4 & 298 & 27.7 & Poor & 51.3 & \\
\hline 5 & 301 & 28.9 & Good & 44 & \\
\hline 6 & 311 & 28.6 & Satisfactory & 48.5 & \\
\hline 7 & 224 & 26.5 & Poor. Narrow bead & 25.5 & \\
\hline \multicolumn{6}{|c|}{ Shielding gas surfacing } \\
\hline 1 & 237 & 26.5 & Good & 42.5 & \multirow{7}{*}{ 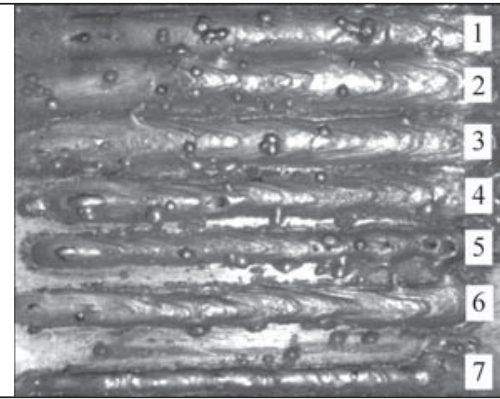 } \\
\hline 2 & 331 & 26.5 & Good & 50 & \\
\hline 3 & 316 & 27.3 & Good & 46 & \\
\hline 4 & 272 & 27.6 & Satisfactory (pores) & 50 & \\
\hline 5 & 171 & 28.3 & Satisfactory (pores) & 49.3 & \\
\hline 6 & 161 & 26.7 & Satisfactory & 50 & \\
\hline 7 & 172 & 23.0 & Satisfactory. Narrow bead & 25.8 & \\
\hline \multicolumn{6}{|c|}{ Open arc surfacing } \\
\hline 1 & 256 & 23.4 & Good & 47.5 & \multirow{6}{*}{ 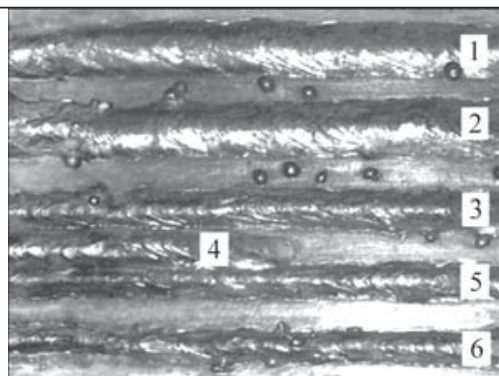 } \\
\hline 2 & 239 & 23.7 & Good & 45.5 & \\
\hline 3 & 227 & 22.3 & Good. Narrow bead & 48 & \\
\hline 4 & 236 & 22.2 & Good. Narrow bead & 38.5 & \\
\hline 5 & 218 & 22.3 & Good. Narrow bead & 51.5 & \\
\hline 6 & 232 & 23.3 & Satisfactory. Narrow bead & 26.5 & \\
\hline
\end{tabular}

er source VDU-506. The surfacing using flux-cored wires of different types and diameters was carried out on the plates of St.3 steel of $15 \mathrm{~mm}$ thickness in a wide range of modes: surfacing current $I_{\mathrm{s}}$ was from 150 to $450 \mathrm{~A}$; voltage $U_{s}$ was from 20 to $34 \mathrm{~V}$. The record and control of electrical parameters of surfacing mode was performed using the developed computer information-measuring system [13]. The surfacing speed of $20 \mathrm{~m} / \mathrm{h}$ in all the experiments remained constant, because in the range of $20-40 \mathrm{~m} / \mathrm{h}$ at other unchanged parameters the surfacing speed almost does not affect the geometric sizes of deposited beads [9].

In the process of the experiments the expert evaluation of quality of deposited bead formation, presence of pores, etc. was carried out. For measurements of basic geometric parameters of deposited beads on macrosections, cut out from deposited workpieces, the instrumental microscope BMI-1 was used. The mean value of $\gamma_{0}$ (VBMD) was determined according to six-eight cross-sections for each deposited bead according to the formula

$$
\gamma_{\mathrm{b}}=\frac{F_{\mathrm{b}}}{F_{\mathrm{b}}+F_{\mathrm{d}}} \cdot 100 \%,
$$

where $F_{\mathrm{b}}, F_{\mathrm{d}}$ are cross-sectional areas of molten base metal and deposited metals, respectively.

The obtained data were entered to the table general for each method. As an example, below the table is presented with characteristics of separate beads, deposited by submerged arc surfacing, surfacing in shielding gases and using open arc with flux-cored wires of $1.8 \mathrm{~mm}$ diameter.

Influence of methods and modes of surfacing on geometric sizes of deposited beads and VBMD. The basic parameters of surfacing mode are: current value, polarity and type; arc voltage; surfacing speed; electrode diameter and surfacing pitch [9]. In surfacing of rotation bodies the basic parameters include also the displacement from zenith (deposition of outer surfaces) or nadir (deposition of inner surfaces).

One of the most important characteristics of surfacing process are penetration value and volume of base metal. It is widely known that with decrease in 
penetration and VBMD not only the consumption of expensive surfacing materials is reduced, but also the quality and operating properties of deposited parts are improved. According to (1), VBMD value depends on the cross-section area of molten base and deposited metal. Thus, VBMD will decrease if the growth of surfacing area occurs faster than the growth of the area of molten base metal.

Figures 1-3 show experimental data on penetration depth of base metal, width of deposited beads and VBMD for the wires of $1.8 \mathrm{~mm}$ (solid lines) and $2.8 \mathrm{~mm}$ diameter (dashed lines) during surfacing using three different methods: submerged arc (a), shielding gas (b) and open arc (c).

As is seen from Figures 1 and 2, the improvement in electric parameters of surfacing mode leads to increase in penetration depth of base metal and width of deposited beads. It is the most significantly manifested in submerged arc surfacing. The increase in current and voltage results in almost proportional increase in
VBMD (Figure 3). This is explained by the fact, that increase in current leads to increase in effective thermal capacity of the arc, due to which the penetration depth and rate of electrode melting are increased.

It was found that at the same mode of surfacing using wire of one diameter, the lower VBMD can be obtained in submerged arc surfacing. Obviously, this is connected with higher thermal efficiency coefficient of this process due to better heat transfer between the arc and the base metal and the absence of heat losses for radiation and spattering the electrode metal. As a result, the growth of surfacing area occurs faster than the growth of the area of molten base metal.

Moreover, to provide the minimum possible penetration considering the quality formation of deposited beads (see below) is possible in the case of open arc surfacing with the wire of $1.8 \mathrm{~mm}$ diameter. Also, it should be noted, that for each method the areas with almost constant or even decreasing VBMD value at the growth of current and voltage are characteristic,
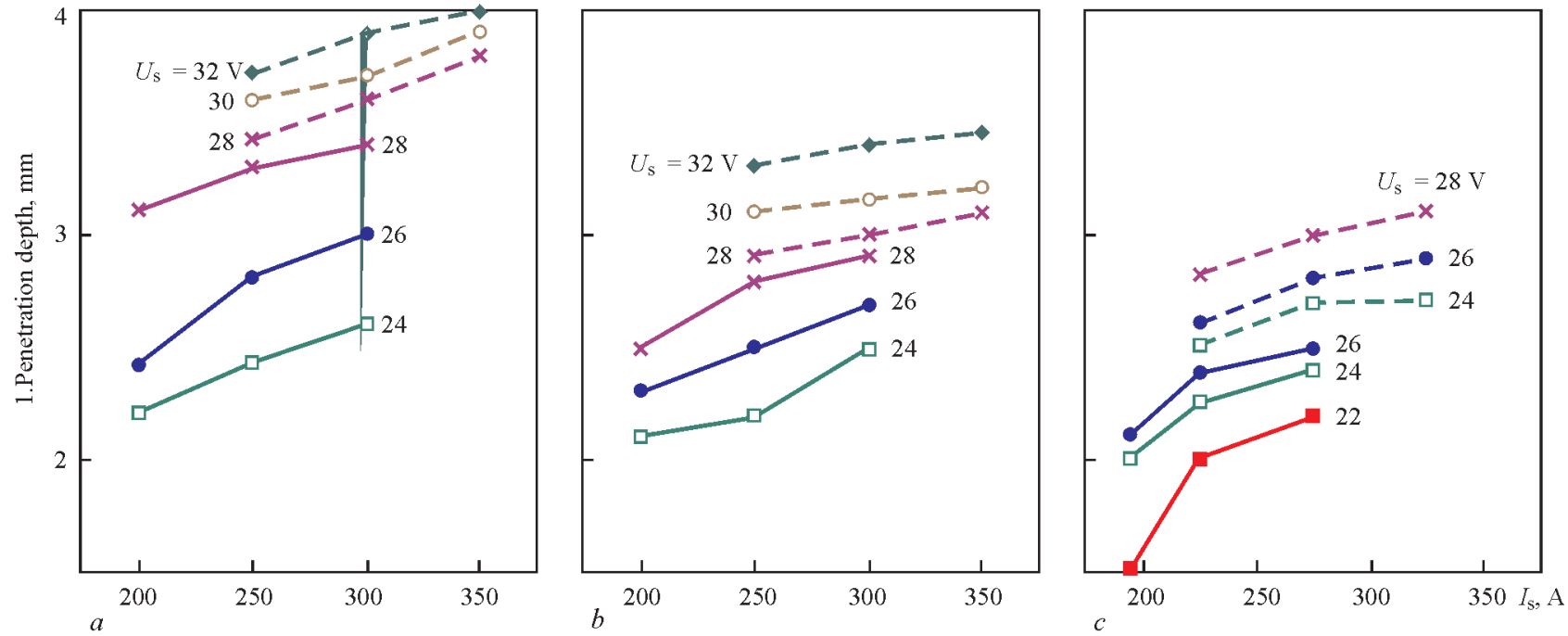

Figure 1. Influence of current on penetration depth in submerged arc surfacing $(a)$, surfacing in shielding gases $(b)$ and using open arc (c) (solid lines — wire of $1.8 \mathrm{~mm}$ diameter; dash lines - $2.8 \mathrm{~mm}$ )
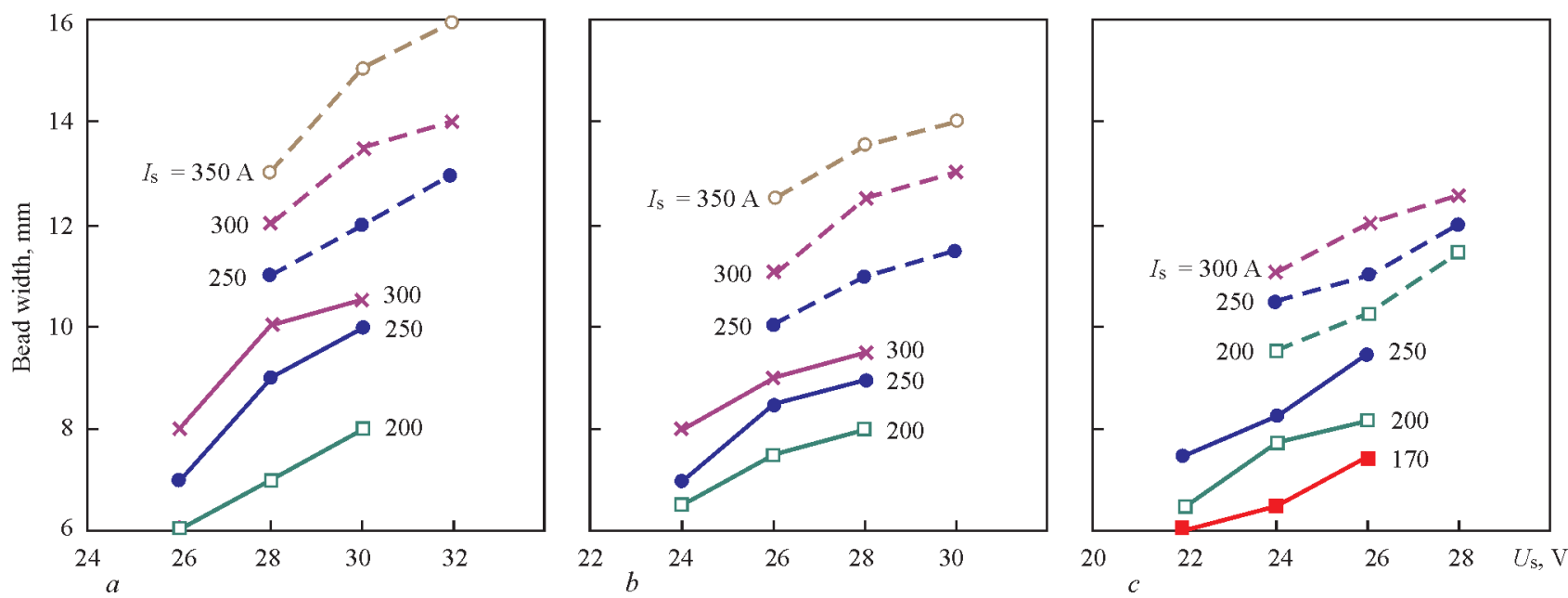

Figure 2. Influence of arc voltage on bead width in submerged arc surfacing $(a)$, surfacing in shielding gases $(b)$ and using open arc $(c)$ (solid lines - wire of $1.8 \mathrm{~mm}$ diameter; dash lines - $2.8 \mathrm{~mm}$ ) 

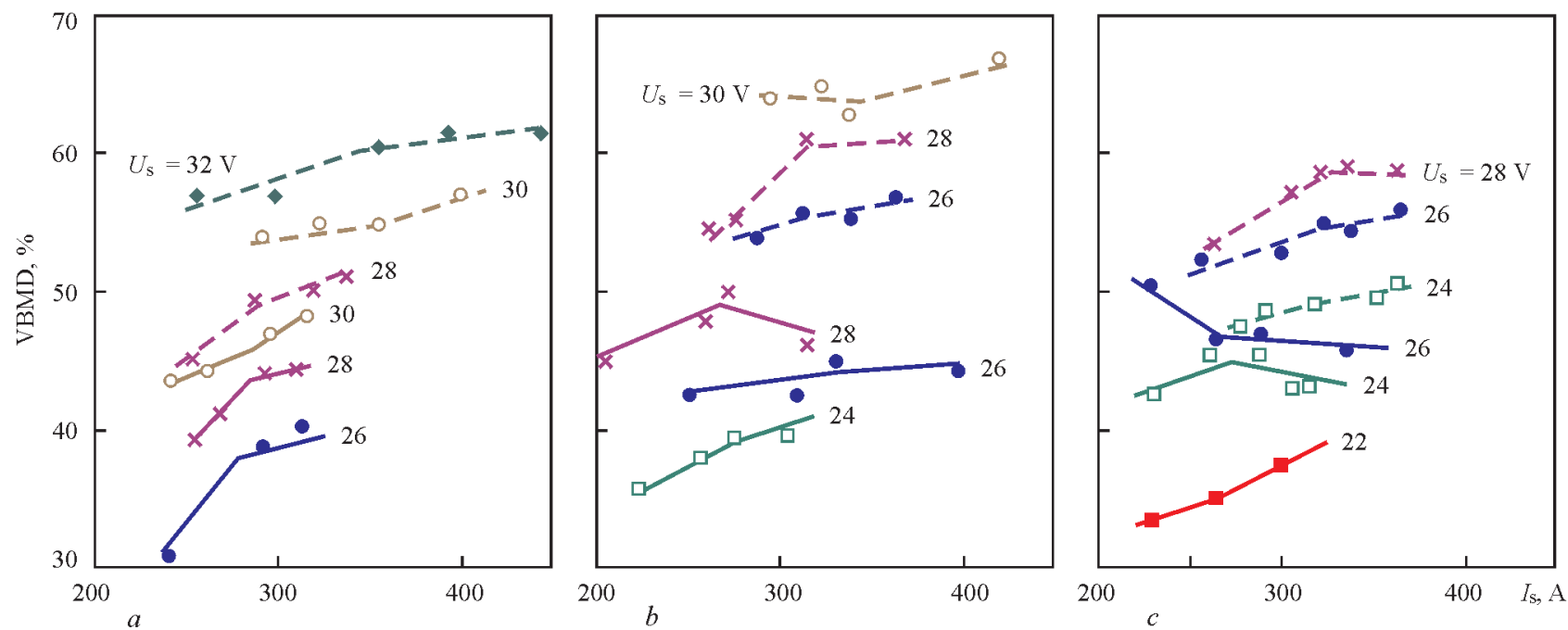

Figure 3. Influence of current and arc voltage on VBMD in submerged arc surfacing $(a)$, surfacing in shielding gases $(b)$ and using open arc (c) (solid lines — wire of $1.8 \mathrm{~mm}$ diameter; dash lines - $2.8 \mathrm{~mm}$ )

which is also explained by the ratio of values of electrical parameters of surfacing modes.

Influence of methods and modes of surfacing on quality of deposited beads formation. Submerged arc surfacing. When using the flux-cored wire of $1.8 \mathrm{~mm}$ diameter a good formation is observed at the conditions: $I_{\mathrm{s}}=220-300 \mathrm{~A}, U_{\mathrm{s}}=28-30 \mathrm{~V}$; for the wire of $2.4 \mathrm{~mm}$ diameter: $I_{\mathrm{s}}=250-350 \mathrm{~A}$, at the same voltage. The reduction of $U_{\mathrm{s}}<28 \mathrm{~V}$, as well as increase in $U_{\mathrm{s}}>30 \mathrm{~V}$ for the wires of the mentioned diameters results, respectively, in too narrow or too wide beads with a non-uniform formation.

For the wire of $2.8 \mathrm{~mm}$ diameter the optimal surfacing mode corresponds to the values $U_{\mathrm{s}}=28-32 \mathrm{~V}$ and $I_{\mathrm{s}}=250-400 \mathrm{~A}$. At the values of voltage $U_{\mathrm{s}}<28 \mathrm{~V}$ and $U_{s}>32 \mathrm{~V}$, the formation of beads is deteriorated, however, even at such «unfavorable» conditions the absence of defects in the deposited metal is observed.

Shielding gas surfacing. In surfacing with fluxcored wire of $1.8 \mathrm{~mm}$ diameter a good formation of deposited beads is observed in the range of modes $U_{\mathrm{s}}$ $=25-27 \mathrm{~V} ; I_{\mathrm{s}}=250-320 \mathrm{~A}$. At the voltage $U_{\mathrm{s}}<25 \mathrm{~V}$

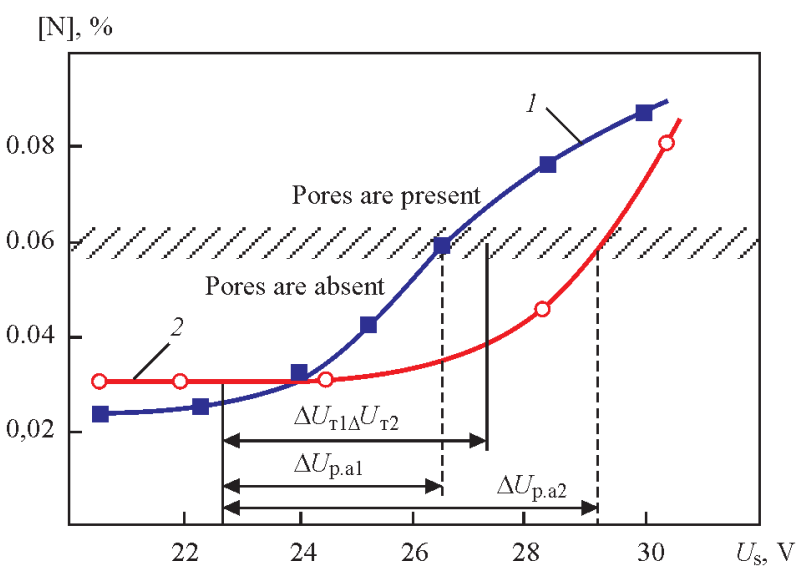

Figure 4. Influence of arc voltage on porosity in deposited metal [4] (see designations in the text) and $U_{s}>27 \mathrm{~V}$ the satisfactory formation and absence of pores are noted, and at increase in voltage by more than $28 \mathrm{~V}$ the pores are appeared in the deposited metal and the formation of beads is poor.

For the wire of $2.4 \mathrm{~mm}$ diameter the range of modes, at which the quality formation of deposited beads is achieved, corresponds to $U_{\mathrm{s}}=26-28 \mathrm{~V} ; I_{\mathrm{s}}=$ $=270-350 \mathrm{~A}$. At the voltage $U_{\mathrm{s}}<25 \mathrm{~V}$ and $U_{\mathrm{s}}>28 \mathrm{~V}$ the formation is satisfactory, the pores are absent.

It is recommended to conduct surfacing using wire of $2.8 \mathrm{~mm}$ diameter at the modes: $U_{\mathrm{s}}=27-29 \mathrm{~V} ; I_{\mathrm{s}}=$ $=270-350 \mathrm{~A}$. In the ranges $U_{\mathrm{s}}=25-26 \mathrm{~V}$ and $U_{\mathrm{s}}=$ $=30-32 \mathrm{~V}$ the formation of deposited beads is satisfactory, the pores are absent. At the voltage $U_{\mathrm{s}}<25 \mathrm{~V}$ and $U_{\mathrm{s}}>32 \mathrm{~V}$ the poor formation of deposited metal and the presence of pores are noted.

Open arc surfacing. For the present method of surfacing in most cases a good formation and the absence of pores are characteristic only for the definite range of surfacing modes. However, in surfacing with open arc, two ranges of modes by arc voltage should be distinguished: $\Delta U_{\mathrm{T}}$ is the range, at which a good formation, minimal spattering, admissible VBMD value and $\Delta U_{\text {p.a }}$ (the range in which the pores are absent) are provided [4].

For different types of deposited metal and compositions, the charges of flux-cored wires $\Delta U_{\mathrm{T}}$ and $\Delta U_{\text {p.a }}$ can differ significantly from each other as to their value. The range of modes, at which $\Delta U_{\mathrm{T}}$ and $\Delta U_{\text {p.a }}$ coincide, is the most preferred for surfacing. As an illustration, Figure 4 shows the influence of arc voltage on the porosity of deposited metal in surfacing using self-shielding wire with the same content of metallic part of the charge, but with a different composition of gas- and slag-forming materials: 1 - rutile, marble, fluorite; 2 - rutile, fluorite, calcium fluorozirconate, mica [4]. 


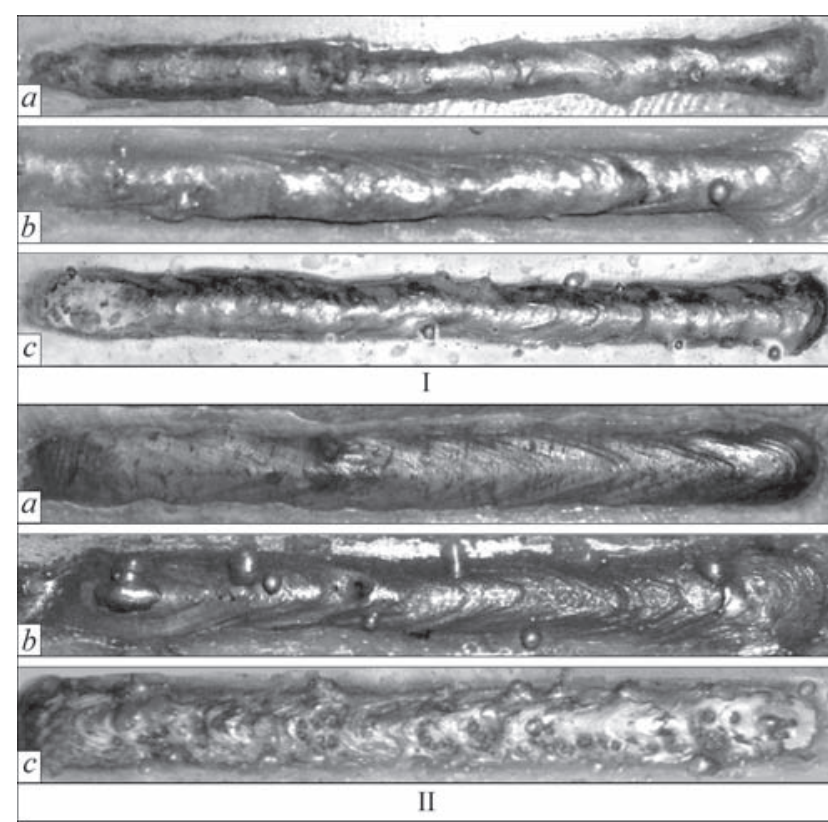

Figure 5. Appearance of beads, deposited using flux-cored wire of $1.8 \mathrm{~mm}$ diameter in submerged arc surfacing $(a)$, surfacing in shielding gases $(b)$, and using open $\operatorname{arc}(c)$ on the modes: $\mathrm{I}-U_{\mathrm{s}}=$ $=24 \mathrm{~V}, I_{\mathrm{s}}=225 \mathrm{~A} ; \mathrm{II}-U_{\mathrm{s}}=28 \mathrm{~V}, I_{\mathrm{s}}=250 \mathrm{~A}$

The carried out investigations showed that for self-shielding wire of $1.8 \mathrm{~mm}$ diameter a good formation of deposited beads and absence of pores are characteristic for the modes $U_{\mathrm{s}}=22-24 \mathrm{~V}$ at the current $I_{\mathrm{s}}=200-250 \mathrm{~A}$. At the voltage $U_{\mathrm{s}}<22 \mathrm{~V}$ the shape of beads is narrow, the formation is satisfactory. At $U_{\mathrm{s}}>24 \mathrm{~V}$ almost in the whole range of currents a significant number of pores and a poor formation of beads are observed. Also at the increase in current and voltage the spattering of metal is increased.

In surfacing with self-shielding flux-cored wires of 2.4 and $2.8 \mathrm{~mm}$ diameter the stable process with a good formation of deposited beads and absence of pores in them is characteristic for surfacing modes $U_{\mathrm{s}}=23-25 \mathrm{~V} ; I_{\mathrm{s}}=220-300 \mathrm{~A}$. For beads, deposited at the modes $U_{\mathrm{s}}<23 \mathrm{~V}$ and $U_{\mathrm{s}}=25-27 \mathrm{~V}$, the absence of pores is also characteristic, but their shape and surface quality can be regarded as not good enough. At the voltage of $U_{\mathrm{s}}>27 \mathrm{~V}$ the process becomes unstable, the beads are characterized by poor formation and the presence of numerous pores.

Thus, for the investigated self-shielding wires the ranges $\Delta U_{\mathrm{T}}$ and $\Delta U_{\text {p.a }}$ almost coincide. The appearance of the most characteristic beads, deposited using flux-cored wires of the diameter of 1.8 and $2.8 \mathrm{~mm}$ at the same modes using three different methods, is shown in Figures 5 and 6.

Based on the obtained data, the conclusion can be made that penetration of base metal is mainly affected by current of surfacing and the quality of deposited metal formation and the stability of surfacing process are affected by arc voltage. Moreover, each diame-

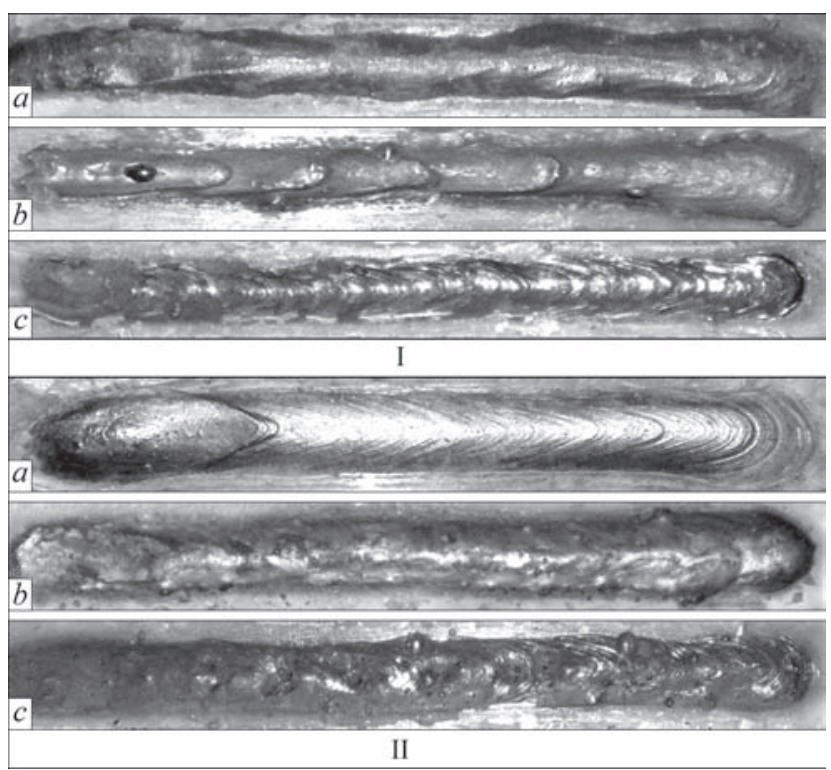

Figure 6. Appearance of beads, deposited using flux-cored wire of $2.8 \mathrm{~mm}$ diameter in submerged arc surfacing $(a)$, surfacing in shielding gases $(b)$, and using open $\operatorname{arc}(c)$ on the modes: $\mathrm{I}-U_{\mathrm{s}}=$ $=24 \mathrm{~V}, I_{\mathrm{s}}=250 \mathrm{~A}$; II $-U_{\mathrm{s}}=28 \mathrm{~V}, I_{\mathrm{s}}=275 \mathrm{~A}$

ter of the wire corresponds to a certain, rather narrow range of $\Delta U_{\mathrm{T}}$ at which a good formation of deposited beads with minimal penetration of base metal is provided. Moreover, as is seen in Figures 5 and 6, this range for different methods of surfacing using wire of the same composition and diameter does not coincide. For example, in surfacing using wire of $1.8 \mathrm{~mm}$ diameter at the mode $U_{s}=24 \mathrm{~V}$ the formation of bead, produced using submerged arc surfacing, is poor, and in surfacing in shielding gases it is satisfactory, whereas in surfacing using self-shielding wire it is good (Figure 5 , mode I). The reverse dependence is seen at the increase in voltage to $28 \mathrm{~V}$ (Figure 5, mode II). The similar regularity is typical in surfacing using wires of 2.4 and $2.8 \mathrm{~mm}$ diameter (Figure 6).

The results obtained in this work, can be used in selection of surfacing modes, which ultimately meet the operation conditions and the requirements to deposited metal for definite parts, and also can be used in the databases when developing computer programs for robotized additive technologies of arc surfacing.

\section{Conclusions}

1. It was established, that the greatest influence on quality of deposited beads formation is exerted by arc voltage. Moreover, the range of $\Delta U_{\mathrm{T}}$ voltage values, at which a good formation of deposited beads is provided, does not coincide in arc surfacing using different methods with the wire of one diameter.

2. The most significant influence of surfacing modes on geometric sizes of beads and penetration of base metal is revealed during submerged arc surfacing. This method provides the widest range of $\Delta U_{\mathrm{T}}$. 
However at the same time it is also characterized by a large penetration depth of base metal. It is possible to provide the minimum possible penetration in quality formation of deposited beads in the case of surfacing using open arc with wire of $1.8 \mathrm{~mm}$ diameter.

3. The optimum ranges of surfacing modes using flux-cored wires were determined, providing producing the high-quality deposited metal of the type 25Kh5FMS with minimum penetration of base metal.

1. Pokhodnya, I.K., Suptel, A.M., Shlepakov, V.N. (1972) Fluxcored wire welding. Kiev: Naukova Dumka.

2. Pokhodnya, I.K., Yavdoshchin, I.R., Paltsevich, A.P. et al. (1994) Metallurgy of arc welding, interaction of metal with gases. Kiev: Naukova Dumka.

3. Pokhodnya, I.K., Shlepakov, V.N., Maksimov, S.Yu. et al. (2010) Research and developments of the E.O. Paton Electric Welding Institute in the field of electric arc welding and surfacing using flux-cored wire (Review). The Paton Welding J., 12, 26-33.

4. Yuzvenko, Yu.A., Kirilyuk, G.A. (1973) Flux-cored wire surfacing. Moscow: Mashinostroenie.

5. Shlepakov, V.N., Gavrilyuk, Yu.A., Kotelchuk, A.S. (2010) State-of-the-art of development and application of flux-cored wires for welding of carbon and low-alloyed steels. The Paton Welding J., 3, 38-42.

6. Shlepakov, V.N. (2014) Physical-metallurgical and welding-technological properties of gas-shielded flux-cored wires in welding of structural steels. Ibid., 6/7, 56-59.

7. Rosert, R. (2014) Application of flux-cored wires for welding under industrial conditions. Ibid., 6/7, 60-64.

8. Kondratiev, I.A., Ryabtsev, I.A. (2014) Flux-cored wires for surfacing of steel rollers for hot rolling. Ibid., 6/7, 99-100.

9. Ryabtsev, I.A. (2004) Surfacing of machine and mechanism parts. Kiev: Ekotekhnologiya.

10. Razikov, M.I. (1962) Automatic $\mathrm{CO}_{2}$ surfacing. Moscow: Mashinostroenie.

11. Demchenko, V.F., Ryabtsev, I.A., Kozlitina, S.S. (1998) Computer system of design of arc surfacing technologies. Avtomatich. Svarka, 11, 61-66.

12. Demchenko, V.F., Ryabtsev, I.A., Kozlitina, S.S. (1999) Computer system of design of technologies for restoration and strengthening of metallurgical equipment parts. Tyazholoe Mashinostroenie, 2, 25-26.

13. Ryabtsev, I.A., Lankin, Yu.N., Soloviov, V.G. et al. (2015) Computer information-and-measuring system for investigation of arc surfacing processes. The Paton Welding J., 9, 32-35.

Received 15.09.2016 